\title{
Normal sleep and circadian rhythms: Neurobiologic mechanisms underlying sleep and wakefulness
}

\author{
Dimitri Markov \\ Thomas Jefferson University \\ Marina Goldman \\ University of Pennsylvania
}

Follow this and additional works at: https://jdc.jefferson.edu/phbfp

Part of the Medicine and Health Commons

\section{Let us know how access to this document benefits you}

\section{Recommended Citation}

Markov, Dimitri and Goldman, Marina, "Normal sleep and circadian rhythms: Neurobiologic mechanisms underlying sleep and wakefulness" (2006). Department of Psychiatry and Human Behavior Faculty Papers. Paper 2.

https://jdc.jefferson.edu/phbfp/2

This Article is brought to you for free and open access by the Jefferson Digital Commons. The Jefferson Digital Commons is a service of Thomas Jefferson University's Center for Teaching and Learning (CTL). The Commons is a showcase for Jefferson books and journals, peer-reviewed scholarly publications, unique historical collections from the University archives, and teaching tools. The Jefferson Digital Commons allows researchers and interested readers anywhere in the world to learn about and keep up to date with Jefferson scholarship. This article has been accepted for inclusion in Department of Psychiatry and Human Behavior Faculty Papers by an authorized administrator of the Jefferson Digital Commons. For more information, please contact: JeffersonDigitalCommons@jefferson.edu. 


\title{
Normal Sleep and Circadian Rhythms: Neurobiologic Mechanisms Underlying Sleep and Wakefulness
}

\author{
Dimitri Markov, MD ${ }^{\mathrm{a}}$, \\ Marina Goldman, MD $^{b}$ \\ a Department of Psychiatry and Human Behavior, Thomas Jefferson University, 1020 \\ Sansom Street, Thompson Building, Suite 1652, Philadelphia, PA 19107-5004, USA \\ b Department of Psychiatry and Human Behavior, University of Pennsylvania, \\ Philadelphia, Pennsylvania \\ * Corresponding author, E-mail address: dimitri.markov@jefferson.edu
}

The cyclic repetition of sleep and wakefulness states is essential to the basic functioning of all higher animals, including humans. As understanding of the neurobiology of sleep increases, clinicians no longer view it as a passive state (ie, sleep as merely the absence of wakefulness). Sleep is an active neurobehavioral state that is maintained through a highly organized interaction of neurons and neural circuits in the central nervous system (CNS).

\section{DEFINING SLEEP}

Sleep physicians define human sleep on the basis of an individual's observed behavior and accompanying physiologic changes in the brain's electrical activity as the brain transitions between wakefulness and sleep. Behaviorally, human sleep is characterized by reclined position, closed eyes, decreased movement, and decreased responsivity to internal and external environment. The responsiveness to stimuli is not completely absent; a sleeper continues to process some sensory information during sleep, and meaningful stimuli are more likely to produce arousals than nonmeaningful ones. A sound of one's own name is more likely to arouse a sleeper than some other sound, and the cry of her infant is more likely to arouse a sleeping mother than a cry of another infant.

\section{CONSTITUENTS OF SLEEP}

Sleep consists of two strikingly different states, rapid-eye-movement (REM) sleep and non-REM (NREM) sleep. NREM sleep can be subdivided further into four stages.

Polysomnography is the "gold standard" technique that simultaneously records the three physiologic measures that define the main stages of sleep and wakefulness. These measures include muscle tone, recorded through electromyogram (EMG); eye

The published version of this paper appeared in Psychiatric Clinics of North American 29(4):841-853, December 2006 (http://www.mdconsult.com/das/clinics/view/0/N/16839638?ja=558771\&PAGE=1.html\&source=). Copyright (C) 2006 Elsevier, Inc. 
movements, recorded through electro-oculogram (EOG); and brain activity, recorded through electroencephalogram (EEG) ${ }^{[1]}$. The clinical polysomnogram, the purpose of which is to detect findings that are characteristic of certain sleep disorders, includes, in addition to these three variables, the following: monitors for airflow at the nose and mouth, respiratory effort strain gauges placed around the chest and abdomen, and noninvasive oxygen saturation monitors that function by introducing a beam of light through the skin. Other parameters include the electrocardiogram and EMG of the anterior tibialis muscles, which are intended to detect periodic leg movements. Finally, a patient's gross body movements are monitored continuously by audiovisual means.

The EEG pattern of drowsy wakefulness consists of low-voltage rhythmic alpha activity (8-13 cycles per second [Hz]). In stage 1 of NREM sleep, the low-voltage mixed frequency theta waves $(4-8 \mathrm{~Hz})$ replace alpha rhythm of wakefulness. Slow asynchronous eye movements are seen on the EOG in the beginning of stage 1 sleep and disappear in a few minutes. The muscle activity is highest during wakefulness and diminishes as sleep approaches. Individuals with behavioral characteristics of sleep and polysomnographic characteristics of stage 1 sleep may or may not perceive themselves as sleeping. Stage 1 is viewed as a "shallow" sleep, during which an individual can be easily aroused. With transition to stage 2, EEG patterns termed sleep spindles and $K$ complexes appear on the EEG. Sleep spindles are 12- to 14-Hz synchronized EEG waveforms with duration of 1.5 seconds. Sleep spindle waves arise as a result of synchronization of groups of thalamic neurons by the GABAergic thalamic spindle pacemaker. The origin of $\mathrm{K}$ complexes is unknown. With the onset of stage 2, the arousal threshold increases, and a more intense stimulus is needed to arouse a sleeper. Stages 3 and 4 of NREM sleep are defined by synchronized high-amplitude $(>75 \mu \mathrm{V})$ and slow $(0.5-2 \mathrm{~Hz})$ delta wave EEG pattern. Stages 3 and 4 collectively are referred as deep sleep, delta sleep, or slow-wave sleep. By definition, delta waves account for $20 \%$ to $50 \%$ of EEG activity during stage 3 and greater than $50 \%$ of EEG activity during stage 4 of sleep. Slow-wave sleep is associated with a higher arousal threshold than "lighter" stages of NREM sleep. No eye movements are detected on the EOG during stages 2, 3, and 4 of NREM sleep. The EMG tracks continued muscle tone decline as NREM sleep "deepens" from stages 1 to 4.

The cortical EEG pattern of REM sleep is characterized by low voltage and fast frequencies (alpha or 8-13 Hz). This EEG pattern is referred as activated or desynchronized and also is seen in the state of relaxed wakefulness (with eyes closed). Activated refers to an active mind (dreams) and the EEG pattern characteristic of wakefulness. Paradoxically, individuals in REM sleep, although activated, are behaviorally less responsive than during the wake state ${ }^{[2],[3]}$. Desynchronized refers to the random-appearing wave pattern seen on the REM sleep EEG, which is contrasted

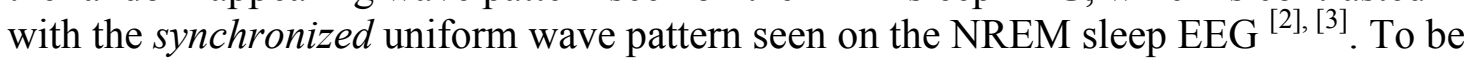
scored as REM sleep, a polysomnographic tracing must contain an activated EEG pattern and muscle atonia (EMG) and the presence of rapid eye movements (EOG). REM sleep can be subdivided further into two stages: tonic and phasic. The tonic stage is continuous and shows muscle atonia and desynchronized EEG as two main features. Superimposed on the tonic stage of REM are intermittent phasic events, which include bursts of rapid eye movements and irregularities of respiration and heart rate. 
Sleep typically begins with a "shallow" stage 1 of NREM sleep and "deepens" to NREM sleep stages 2, 3, and 4, which are followed by the first brief episode of REM sleep in approximately 90 minutes. After the first sleep cycle, NREM and REM sleep continue to alternate in a predictable fashion, each NREM-REM cycle lasting approximately 90 to 120 minutes [1]. In the course of the night, sleep cycles recur three to seven times. Stage 1 of NREM sleep, which lasts only a few minutes, serves as a transition from wakefulness to sleep and later during sleep serves as a transition between REM-NREM sleep cycles. Typically, stage 1 constitutes $2 \%$ to $5 \%$ of total sleep time. An increase in the amount or percentage of stage 1 sleep may be a sign of sleep disruption. The brief first period of stage 1 NREM sleep is followed by "deeper" stage 2, which lasts approximately 10 to 20 minutes. Stage 2 sleep normally constitutes $45 \%$ to $55 \%$ of the total sleep time. Stage 2 sleep progresses to stages 3 (lasting a few minutes) and 4 (lasting 40 minutes). Stage 3 constitutes $5 \%$ to $8 \%$ of the total sleep time, and stage 4 constitutes $10 \%$ to $15 \%$ of the total sleep time. Stages 3 and 4 of NREM sleep predominate during the first third of the night. The first REM period is brief and occurs approximately 90 minutes after sleep onset; subsequent REM cycles occur approximately 90 to 120 minutes apart. REM sleep episodes become longer as the night progresses, and the longest REM periods are found in the last third of the night ${ }^{[4],[5]}$. NREM sleep accounts for $75 \%$ to $80 \%$ and REM sleep accounts for $20 \%$ to $25 \%$ of the total sleep time ${ }^{[1],[3],[6],[7],[8]}$. These proportions commonly vary with age (see later section on effects of age).

\section{PHYSIOLOGIC FUNCTIONS IN SLEEP}

\section{AUTONOMIC NERVOUS SYSTEM DURING SLEEP}

The parasympathetic drive is higher during all stages of sleep than in relaxed wakefulness. The sympathetic drive increases significantly during phasic REM, decreases slightly during tonic REM, and remains relatively unchanged during relaxed wakefulness and NREM sleep. The net effect is the dominance of the parasympathetic tone during NREM and tonic REM sleep, and the sympathetic dominance during phasic REM ${ }^{[9],[10] \text {, }}$ [11].

\section{BODY TEMPERATURE REGULATION}

The energy expenditure is lower during NREM sleep compared with wakefulness. The body temperature is maintained at a lower set-point in NREM than in wakefulness. During REM sleep, thermoregulatory responses of shivering and sweating are absent, and thermal regulation seems to cease (as in poikilothermic organisms) ${ }^{[9],[10],[11]}$.

\section{CONTROL OF RESPIRATION AND CARDIOVASCULAR FUNCTION DURING SLEEP}

The predominance of the parasympathetic tone and decreased energy expenditure during NREM sleep are responsible for decreased ventilation during this stage. The respiration 
rate in NREM sleep is regular, and cardiovascular changes are consistent with decreased energy expenditure. In contrast, breathing patterns and heart rate during REM sleep are irregular [9], [10], [11]. The irregularities in cardiovascular parameters increase the risk of myocardial infarctions during REM sleep in vulnerable individuals. The changes in ventilation, respiration, and upper airway tone make REM sleep a vulnerable period for individuals with obstructive sleep apnea (Table 1).

\section{EFFECTS OF AGE}

Age is likely the strongest factor that affects sleep continuity and the distribution of sleep stages through the night. The sleep pattern of newborn infants dramatically differs from that of adults. During the first year of life, infants sleep twice as much as adults and, in contrast to adults, enter sleep through REM. During the first year of life, REM sleep constitutes $50 \%$ of the total sleep time; the percentage occupied by REM sleep decreases to adult levels of $20 \%$ to $25 \%$ by age 3 years and remains at that level until old age. NREM-REM cycles, controlled by the ultradian process, are present at birth, but the 50to 60-minute cycle periods in newborns are shorter than the approximately 90 -minute periods in adults. Slow-wave sleep is not present at birth, but develops by age 2 to 6 months. The amount of slow-wave sleep steadily declines from maximal levels in the young to almost nonexistent amounts in the elderly ${ }^{[1],[10],[12]}$. In addition to loss of slowwave sleep, sleep changes in the elderly include sleep fragmentation, increased percentage of stage 1 sleep, and decreased ability to maintain continuous sleep at night and wakefulness during the day. Contrary to commonly held beliefs, the need to sleep does not decrease with the advancing age; what changes in the elderly is the ability to maintain sleep (Fig. 1) ${ }^{[10],[12],[13]}$.

\section{HOW MUCH SLEEP DOES ONE NEED?}

One needs a sufficient amount of sleep to feel alert and refreshed and to avoid falling asleep unintentionally during the waking hours. Most young adults average 7 to 8 hours of sleep nightly, but there is a significant individual and night-to-night variability in these figures. Genetics plays a role in determining sleep length, and voluntary sleep reduction plays a significant role in determining how much sleep an individual actually gets. Sleep restriction results in daytime sleepiness, and daytime sleepiness suggests that an individual's sleep needs have not been met ${ }^{[1]}$.

\section{REGULATION OF SLEEP AND WAKEFULNESS}

\section{DRIVES}

Experimental studies in humans and animals led to the development of the two-process model, which accounts for regulation of sleep and wake time. According to the model, sleep is regulated by two basic processes: a homeostatic process, which depends on the amount of prior sleep and wakefulness, and a circadian process, which is driven by an endogenous circadian pacemaker, generating nearly 24-hour cycles of behavior. An 
ultradian process within sleep is believed to control the alternation between REMNREM sleep every 90 to 120 minutes. It is hypothesized that the interaction of homeostatic and circadian processes is responsible for helping humans to maintain wakefulness during the day and consolidated sleep at night (Fig. 2).

\section{HOMEOSTATIC REGULATION OF SLEEP}

Virtually all organisms have an absolute need to sleep. Humans cannot remain awake voluntarily for longer than 2 to 3 days, and rodents cannot survive without sleep for longer than few weeks ${ }^{[10],[14]}$. The homeostatic factor represents an increase in the need for sleep (sleep pressure) with increasing duration of prior wakefulness. The presence of homeostatic factor is best shown through sleep deprivation studies. When a normal amount of sleep is reduced, the homeostatic drive is increased, leading to increased sleep pressure and sleepiness during the day and increased deep sleep at night. When normal sleep is preserved, the homeostatic factor represents a basic increase in sleep propensity during waking hours. The pull of this drive builds up during wakefulness and reaches its peak at sleep time. Its strength declines during sleep with the lowest point (nadir) on awakening in the morning.

It also is useful to differentiate sleepiness from tiredness or fatigue. A tired or fatigued individual does not have a propensity to fall asleep given an opportunity to do so. A sleepy individual is not only anergic, but also falls asleep given the opportunity to do so.

\section{CIRCADIAN RHYTHMS}

Humans have an endogenous circadian pacemaker with an intrinsic period of slightly more than 24 hours ${ }^{[15]}$. Virtually all living organisms exhibit metabolic, physiologic, and behavioral circadian (ie, about 24 hours) rhythms. The most obvious circadian rhythm is the human sleep-wake cycle. Examples of other circadian rhythms include the release of cortisol, thyroid-stimulating hormone, and melatonin. Most mammalian tissues and organs contain mechanisms capable of expressing their function in accordance with the circadian rhythm. The "master biologic clock," which regulates sleep-wake and all other circadian rhythms, resides in the suprachiasmatic nuclei ( $\mathrm{SCN}$ ) of the hypothalamus. SCN are bilaterally paired nuclei located slightly above the optic chiasm in the anterior hypothalamus.

Circadian clocks normally are synchronized to environmental cues (zeitgebers) by a process called entrainment. The process of entrainment of SCN cells is mediated through glutamate stimulating the $N$-methyl-D-aspartate receptor ${ }^{[16]}$. Light hitting the retina activates the release of glutamate through the retinohypothalamic tract projecting to the SCN [17]. In most mammals and humans, light-dark cycle is the most potent entraining stimulus. The modulation of the SCN by environmental cues and neurotransmitters/hormones is phase dependent. When light is given to a patient at night, it shifts the circadian clock back, whereas light exposure in early morning shifts the clock forward; melatonin is effective only in shifting the circadian clock when given at dawn or 
at dusk, but not during the daytime hours; cholinergic activation of the muscarinic receptors affects the clock only at night ${ }^{[18],[19]}$.

Circadian information from the SCN is transmitted to the rest of the body after input from the hypothalamus. Body organ responses (eg, sleep-wake cycle, core body temperature, the release of cortisol, thyroid-stimulating hormone, melatonin) to the circadian rhythm is controlled by the SCN and modulated by the hypothalamus. The release of melatonin from the pineal gland, signaled by the circadian rhythm, peaks at dawn and dusk. The SCN contains melatonin receptors, and the circadian clock can be reset by melatonin through a feedback mechanism ${ }^{[15],[18],[20]}$. In the absence of environmental cues (eg, under conditions of sensory deprivation), the endogenous rhythmicity of the circadian pacemaker persists independently of the light-dark cycle ${ }^{[18],[21]}$. The genes of the SCN cells, through transcription-translation, are responsible for maintaining the 24-hour clock. Experimental mutation of these genes in animals produces prolonged or shortened circadian periods, whereas in humans such mutations result in abnormal circadian rhythms ${ }^{[18]}$.

\section{NEUROTRANSMITTERS INVOLVED IN SLEEP AND WAKEFULNESS}

Adenosine had been identified as a possible mediator of the homeostatic sleep process. It is an endogenous sleep-producing substance ${ }^{[10],[18],[22],[23],[24]}$. A breakdown product of adenosine triphosphate (ATP), adenosine is believed to be a homeostatic sleep factor that mediates the transition from prolonged wakefulness to NREM sleep. Adenosine mediates this transition by inhibiting arousal-promoting neurons of the basal forebrain. Caffeine is believed to promote wakefulness by blocking adenosine receptors. ATP is an important energy reserve in neurons. Adenosine accumulates in certain areas of the brain when neurons consume energy in the form of ATP during prolonged wakefulness. In animal studies, adenosine levels in the brain increased during sleep deprivation and returned to baseline during sleep ${ }^{[14],[25], \text { [26] }}$. Other substances hypothesized to be involved in promoting sleep and contributing to the homeostatic factor include proinflammatory cytokines (interleukin-1) ${ }^{[18], \text { [27] }}$ prostaglandin $\mathrm{D}_{2}$, and growth hormone-releasing hormone ${ }^{[27]}$.

Cholinergic neurons have a dual role: Some promote sleep, and others promote wakefulness. The serotoninergic, noradrenergic, and histaminergic wakefulnesspromoting neurons have a discharge pattern nearly opposite that of the cholinergic sleeppromoting neurons. The discharge rate of serotoninergic, noradrenergic, and histaminergic neurons is fastest during wakefulness, decreases during NREM sleep, and virtually stops firing during REM sleep. Additionally, newly discovered peptides called hypocretins (also known as orexins) are thought to regulate wakefulness by interacting with histaminergic, aminergic, and cholinergic systems (Fig. 3).

\section{ACETYLCHOLINE}

Cholinergic neurons that originate in the laterodorsal and pedunculopontine tegmental nuclei (LDT/PPT) of the midbrain reticular formation reach the cortex by ascending 
through the thalamus and hypothalamus. These midbrain LDT and PPT areas contain two interspersed subsets of cholinergic neurons. One subset is responsible for the fastfrequency and low-voltage EEG pattern of "cortical activation," which appears in REM sleep and restful wakefulness. These are called wake/REM-on neurons ${ }^{[28]}$. The second subset is responsible for generations of REM sleep. These latter cholinergic neurons are called REM-on cells. The three physiologic components of REM sleep (muscle atonia, rapid eye movements, EEG activation/desynchronization) are controlled by different nulei located in the pontine reticular formation (PRF). The REM-on cholinergic neurons promote REM sleep by sending excitatory input to the PRF. This causes the rapid firing of the PRF, which produces the three cardinal physiologic components of REM sleep. The PRF is shut off during NREM sleep.

Cholinergic neurons that project from the basal forebrain to the cerebral cortex and limbic areas are part of the vigilance-waking system. The side effects produced by anticholinergic medications likely result owing to a disruption of the vigilance-wake producing cholinergic neurons and the wake/REM-on cholinergic neurons.

\section{SEROTONIN AND NOREPINEPHRINE}

Serotoninergic neurons originate in the dorsal raphe nucleus and noradrenergic neurons originate in the locus caeruleus. Both sets of neurons act as suppressants of REM sleep (REM off cells) by inhibiting REM-promoting cholinergic neurons and by sending inhibitory input to the PRF. Serotonin and norepinephrine neurons promote cortical activation during wakefulness by rapid firing ${ }^{[29]}$. The noradrenergic wake-promoting system also was found to have an important role in the cognitive function of learning during the waking state. Activity of the noradrenergic system triggers an increase in the expression of genes associated with memory formation and learning ${ }^{[18]}$. The serotoninergic system was not found to have this close link to cognitive function.

During the NREM sleep period, at the beginning of the first sleep cycle, the serotoninergic and noradrenergic neurons significantly reduce their firing rate. This removes the inhibition from the REM-on cholinergic neurons; leading to the first REM sleep period approximately 90 minutes later.

\section{HYPOCRETIN}

Hypocretins (also called orexins) are two neuropeptides (hypocretin 1 and hypocretin 2) with key roles in regulation of arousal and metabolism. They bind to their corresponding receptors (Hcrtrl and Hcrtr2) throughout the brain and spinal cord. These peptides are produced by hypothalamic neurons that surround the fornix bilaterally and in the dorsolateral hypothalamus. These hypothalamic regions are implicated in control of nutritional balance, blood pressure, and temperature regulation and endocrine secretion and arousal. Hypocretins likely play a role in all of these functions ${ }^{[30]}$.

The hypocretin-producing neurons in the hypothalamus receive direct input from the SCN (the circadian rhythm clock) and project to the posterior hypothalamus 
(tuberomammillary nucleus [TMN]-histamine), basal forebrain (cholinergic vigilancewake area), thalamus, locus caeruleus and dorsal raphe neucleus (norepinephrine and serotonin REM off cells), LDT, and PRF (cholinergic REM-on cells and muscle atonia) [30], [31]. In accordance with circadian rhythm control of hypocretin levels (through SCN input), their concentration is highest during the waking period. Hypocretin levels also increase during a period of forced sleep deprivation. It is unclear whether this increase during sleep deprivation represents hypocretin opposing and attempting to override the sleep drive or producing a stress response to sleep deprivation. Hypocretin input to the brainstem REM-on cells controls the switch into REM by reducing the firing rate of the REM-on cells during the wake period ${ }^{[30]}$.

\section{HISTAMINE}

Antihistaminergic drugs that cross the blood-brain barrier are known to produce sedation. The neurotransmitter histamine plays a key role in maintenance of wakefulness.

Histaminergic neurons originate from the TMN of the posterior hypothalamus and project diffusely throughout the brain. In the cortex, histamine facilitates cortical arousal. Histaminergic neurons fire most rapidly during cortical activation in the wake state and turn off during REM sleep ${ }^{[29], \text { [32]. }}$

\section{HYPOTHALAMUS}

The role of the hypothalamus as a key area of the brain involved in regulation of sleep and wakefulness was recognized after the pandemic of encephalitis lethargica swept the world in the early 1900s. Thought to be a viral infection of the brain, encephalitis lethargica induced severe sleep abnormalities in affected individuals. Most patients exhibited profound and prolonged sleepiness, whereas some had severe insomnia. Patients affected by sleepiness were discovered to have lesions in the posterior hypothalamus; patients affected by insomnia were found to have lesions in the anterior hypothalamus ${ }^{[23],[33]}$.

Since this clinical observation more than 70 years ago, numerous human and animal studies have elucidated further the role of the hypothalamus in the regulation of sleep. In accordance with these original observations, the ventrolateral preoptic nucleus in the anterior hypothalamus has been established as the key sleep-inducing region and the TMN of the posterior hypothalamus as one of the important wakefulness-promoting regions of the brain.

The anterior hypothalamus contains GABAergic cells. Activity of GABAergic cells in the ventrolateral preoptic nucleus region is implicated in production of NREM sleep, whereas the GABAergic cells in the area adjacent to the ventrolateral preoptic nucleus is thought to promote REM sleep by inhibiting the noradrenergic (locus caeruleus) and serotoninergic (dorsal raphe nucleus) REM-off nuclei of the brainstem ${ }^{[23]}$. The rapid firing of the anterior hypothalamus region during sleep leads to inhibition of the locus caeruleus and dorsal raphe nucleus in the brainstem. This in effect takes the 
"noradrenergic and serotoninergic breaks" off the hypothalamic sleep generator, reinforcing the sleep state ${ }^{[33]}$.

The posterior hypothalamus/TMN receives histaminergic input and has hypocretin receptors (hctr2). Histamine and hypocretin produce activation of the TMN cells, which leads to sustained wakefulness ${ }^{[23]}$. At the same time, hypocretin activates the noradrenergic and seretoninergic cells in the brainstem, which send inhibitory signals to the anterior hypothalamus. This in effect takes the "GABAergic breaks" off the hypothalamic wakefulness generator, reinforcing the wake state.

From the point of view of evolutionary advantage, it may be important for most animals to be either in the fully awake or the fully asleep state and to spend little time in the transition state between sleep and wakefulness. The anterior and posterior regions of the hypothalamus work through a system of mutual inhibition in what has been referred to as a flip-flop switch (similar to a light switch) ${ }^{[33]}$. The hypothalamic sleep switch is quickly turned "on" and "off," with both positions being equally stable. It is hypothesized that the circadian, homeostatic, and ultradian drives are responsible for flipping the hypothalamic switch into the sleep and wake positions. The hypocretin tone, which also is influenced by the circadian and homeostatic drives, helps to stabilize the hypothalamic switch in the wake position and prevent intrusion of REM sleep into the waking state ${ }^{[23],[33]}$. When the hypocretin tone is reduced, as in narcolepsy, this stability of the wake state is impaired resulting in abnormal shifts from wake to REM states (eg, cataplexy, sleep paralysis).

\section{PHARMACEUTICALS AND RECREATIONAL DRUGS}

All drugs that cross the blood-brain barrier may affect sleep. Selective serotonin reuptake inhibitors, tricyclic antidepressants, serotonin norepinephrine reuptake inhibitors, and monoamine oxidase inhibitors suppress REM sleep; acute withdrawal from these antidepressants is likely to produce a rebound increase in REM sleep. Barbiturates increase slow-wave sleep and suppress REM. Benzodiazepines suppress slow-wave sleep and do not affect REM. Psychostimulants, such as amphetamine and cocaine, increase sleep latency, fragment sleep, and suppress REM sleep ${ }^{[4],[10],[12]}$.

\section{SLEEPING AND DREAMING}

Many theories attempt to explain the biologic function of sleep, without a clear winner. One such theory posits that sleep serves a restorative function for the brain and body. Normal sleep is subjectively associated with feeling refreshed on awakening. REM sleep is associated with increased CNS synthesis of proteins and is crucial for the CNS development of infants and young humans and animals. Growth hormone secretion is increased, while cortisol secretion is decreased during sleep. All these can be used to support the restorative theory of sleep ${ }^{[34]}$. Another theory of sleep function proposes that sleep has a central role in reinforcement and consolidation of memory. Sleep deprivation experiments have highlighted the important role of REM sleep in memory function ${ }^{[34]}$. 
Another theory suggests that sleep is important for thermoregulatory function. Experiments have shown that total sleep deprivation results in thermoregulatory abnormalities, NREM sleep maintains thermoregulatory function, and REM sleep is associated with impaired thermoregulatory responses (eg, shivering, sweating) ${ }^{[34]}$.

Since the middle 1950s, when REM sleep was identified, sleep research has focused on understanding the physiology of dreams. Most dreams (about 80\%) occur during REM sleep; the remainder occur during NREM sleep. REM sleep dreams are more complex, have more emotional valence, can be bizarre, and are easier to recall. NREM sleep dreams are more logical and realistic, but more difficult to recall possibly because awakening from NREM sleep leaves a person feeling more confused and disoriented than awakening from REM sleep. During REM sleep, neuronal signals originating from the brainstem are transmitted to the cerebral hemispheres and stimulate the cortical association areas to produce images that compose dreams ${ }^{[34]}$.

\section{SUMMARY}

Sleep is a vital, highly organized process regulated by complex systems of neuronal networks and neurotransmitters. Sleep plays an important role in the regulation of CNS and body physiologic functions. Sleep architecture changes with age and is easily susceptible to external and internal disruption. Reduction or disruption of sleep can affect numerous functions varying from thermoregulation to learning and memory during the waking state.

\section{REFERENCES:}

[1] Sinton C.M., McCarley R.W.: Neurophysiological mechanisms of sleep and wakefulness: a question of balance. Semin Neurol 24: 211-223, 2004; Abstract.

[2] Doghramji K.: The evaluation and management of sleep disorders. In: Stoudemire A., ed. Clinical psychiatry for medical students. Lippincott: Philadelphia, 1998: 783-818.

[3] Siegel J.M.: REM sleep. In: Kryger M.H., Roth T., Dement W.C., ed. Principles and practice of sleep medicine. Saunders: Philadelphia, 2005: 120-135.

[4] Carskadon M.A., Dement W.C.: Normal human sleep: an overview. In: Kryger M.H., Roth T., Dement W.C., ed. Principles and practice of sleep medicine. Saunders: Philadelphia, 2005: 13-23.

[5] Markov D., Jaffe F., Doghramji K.: Update on parasomnias: a review for psychiatric practice. Psychiatry 3: 69-76, 2006. 
[6] Carskadon M.A., Rechtschaffen A.: Monitoring and staging human sleep. In: Kryger M.H., Roth T., Dement W.C., ed. Principles and practice of sleep medicin. Saunders: Philadelphia, 2005: 1359-1377.

[7] Chokroverty S.: An overview of sleep. In: Chokroverty S., ed. Sleep disorders medicine: basic science, technical considerations, and clinical aspect. Butterworth Heinemann: Boston, 1999: 7-20.

[8] Walczak T., Chokroverty S.: Electroencephalography, electromyography, and electro-oculography: general principles and basic technology. In: Chokroverty S., ed. Sleep disorders medicine: basic science, technical considerations, and clinical aspects. Butterworth Heinemann: Boston, 1999: 175-203.

[9] Chokroverty S.: Physiologic changes in sleep. In: Chokroverty S., ed. Sleep disorders medicine: basic science, technical considerations, and clinical aspect. Butterworth Heinemann: Boston, 1999: 95-126.

[10] Roth T., Roehrs T.: Sleep organization and regulation. Neurology 54. (Suppl 1): S2-S7.2000; Full Text

[11] Parmeggiani P.L.: Physiology in sleep. In: Kryger M.H., Roth T., Dement W.C., ed. Principles and practice of sleep medicine. Saunders: Philadelphia, 2005: 185-191.

[12] Roth T.: Characteristics and determinants of normal sleep. J Clin Psychiatry 65. (Suppl 16): 8-11, 2004.

[13] Bliwise D.L.: Normal aging. In: Kryger M.H., Roth T., Dement W.C., ed. Principles and practice of sleep medicine. Saunders: Philadelphia, 2005: 24-38.

[14] Porkka-Heiskanen T., Strecker R.E., Thakkar M., et al: Adenosine: a mediator of the sleep-inducing effects of prolonged wakefulness. Science 276: 1265-1268, 1997; Abstract.

[15] Czeisler C.A., Duffy J.F., Shanahan T.L., et al: Stability, precision, and near-24hour period of the human circadian pacemaker. Science 284: 2177-2181, 1999; Abstract.

[16] Hattar S., Liao H.W., Takao M., et al: Melanopsin-containing retinal ganglion cells: architecture, projections, and intrinsic photosensitivity. Science 295: 1065-1070, 2002; Abstract.

[17] Berson D.M., Dunn F.A., Takao M.: Phototransduction by retinal ganglion cells that set the circadian clock. Science 295: 1070-1073, 2002; Abstract. 
[18] Pace-Schott E.F., Hobson J.A.: The neurobiology of sleep: genetics, cellular physiology and subcortical networks. Nat Rev Neurosci 3: 591-605, 2002; Citation.

[19] Brzezinski A.: Melatonin in humans. N Engl J Med 336: 186-195,1997; Citation.

[20] Reiter R.J.: Melatonin: clinical relevance. Best Pract Res Clin Endocrinol Metab 17: 273-285, 2003; Abstract.

[21] Reppert S.M., Weaver D.R.: Molecular analysis of mammalian circadian rhythms. Annu Rev Physiol 63: 647-676, 2001; Abstract.

[22] Borbely A.A., Achermann P.: Sleep homeostasis and models of sleep regulation. $J$ Biol Rhythms 14: 557-568, 1999; Abstract.

[23] Mignot E., Taheri S., Nishino S.: Sleeping with the hypothalamus: emerging therapeutic targets for sleep disorders. Nat Neurosci 5. (Suppl): 1071-1075, 2002; Abstract.

[24] Borbely A.A., Achermann P.: Sleep homeostasis and models of sleep regulation. In: Kryger M.H., Roth T., Dement W.C., ed. Principles and practice of sleep medicine. Saunders: Philadelphia, 2005: 405-417.

[25] Boutrel B., Koob G.F.: What keeps us awake: the neuropharmacology of stimulants and wakefulness-promoting medications. Sleep 27: 1181-1194, 2004; Abstract.

[26] Porkka-Heiskanen T., Alanko L., Kalinchuk A., et al: Adenosine and sleep. Sleep Med Rev 6. 321-332, 2002.

[27] McGinty D., Szymusiak R.: Sleep-promoting mechanisms in mammals. In: Kryger M.H., Roth T., Dement W.C., ed. Principles and practice of sleep medicine. Saunders: Philadelphia, 2005: 169-184.

[28] McCarley R.W.: Sleep neurophysiology: basic mechanisms underlying control of wakefulness and sleep. In: Chokroverty S., ed. Sleep disorders medicine: basic science, technical considerations, and clinical aspects. Butterworth Heinemann: Boston, 1999: 21-50.

[29] Jones B.E.: Basic mechanisms of sleep-wake states. In: Kryger M.H., Roth T., Dement W.C., ed. Principles and practice of sleep medicine. Saunders: Philadelphia, 2005: 136-153.

[30] Sutcliffe J.G., de Lecea L.: The hypocretins: setting the arousal threshold. Nat Rev Neurosci 3: 339-349, 2002; Abstract.

[31] Peyron C., Tighe D.K., van den Pol A.N., et al: Neurons containing hypocretin 
(orexin) project to multiple neuronal systems. J Neurosci 18. 9996-10015, 1998; Abstract.

[32] Siegel J.M.: The neurotransmitters of sleep. J Clin Psychiatry 65. (Suppl 16): 4-7, 2004; Abstract.

[33] Saper C.B., Chou T.C., Scammell T.E.: The sleep switch: hypothalamic control of sleep and wakefulness. Trends Neurosci 24: 726-731, 2001; Abstract.

[34] Chokroverty S.: An overview of normal sleep. In: Chokroverty S., Wayne A.H., Walters A.S., ed. Sleep and movement disorder. Butterworth Heinemann: Philadelphia, 2003: 23-43.

[35] Catesby J.W., Hirshkowitz M.: Assessment of sleep-related erections.

In: Kryger M.H., Roth T., Dement W.C., ed. Principles and practice of sleep medicine, Saunders: Philadelphia, 2005: 1394-1402.

Table 1 -- Physiologic changes with stages of sleep

\begin{tabular}{|c|c|c|}
\hline Parameter & NREM & REM \\
\hline Heart & Decreases & $\begin{array}{l}\text { Irregular with increases and } \\
\text { decreases }\end{array}$ \\
\hline Blood pressure & Unchanged and stable & $\begin{array}{l}\text { Irregular with increases and } \\
\text { decreases }\end{array}$ \\
\hline Respiration & Decreased rate & Irregular rate in phasic stage \\
\hline Ventilation & $\begin{array}{l}\text { Decreased tidal volume; } \\
\text { decreased hypoxic response }\end{array}$ & $\begin{array}{l}\text { Decreased tidal volume in } \\
\text { phasic stage; decreased } \\
\text { hypoxic response }\end{array}$ \\
\hline Upper airway muscle tone & Decreased & Further decreased \\
\hline Temperature & Preserved thermoregulation & $\begin{array}{l}\text { Increased temperature and } \\
\text { poikilothermia }\end{array}$ \\
\hline Pupils & Constricted & $\begin{array}{l}\text { Constricted in tonic stage; } \\
\text { dilated in phasic stage }\end{array}$ \\
\hline Gastrointestinal & $\begin{array}{l}\text { Failure of inhibition of acid } \\
\text { secretion; prolonged acid } \\
\text { clearance }\end{array}$ & $\begin{array}{l}\text { Failure of inhibition of acid } \\
\text { secretion }\end{array}$ \\
\hline $\begin{array}{l}\text { Nocturnal penile } \\
\text { tumescence/clitoral } \\
\text { enlargement }\end{array}$ & Infrequent & Frequent \\
\hline
\end{tabular}

Data From Refs. ${ }^{[9],[35]}$. 


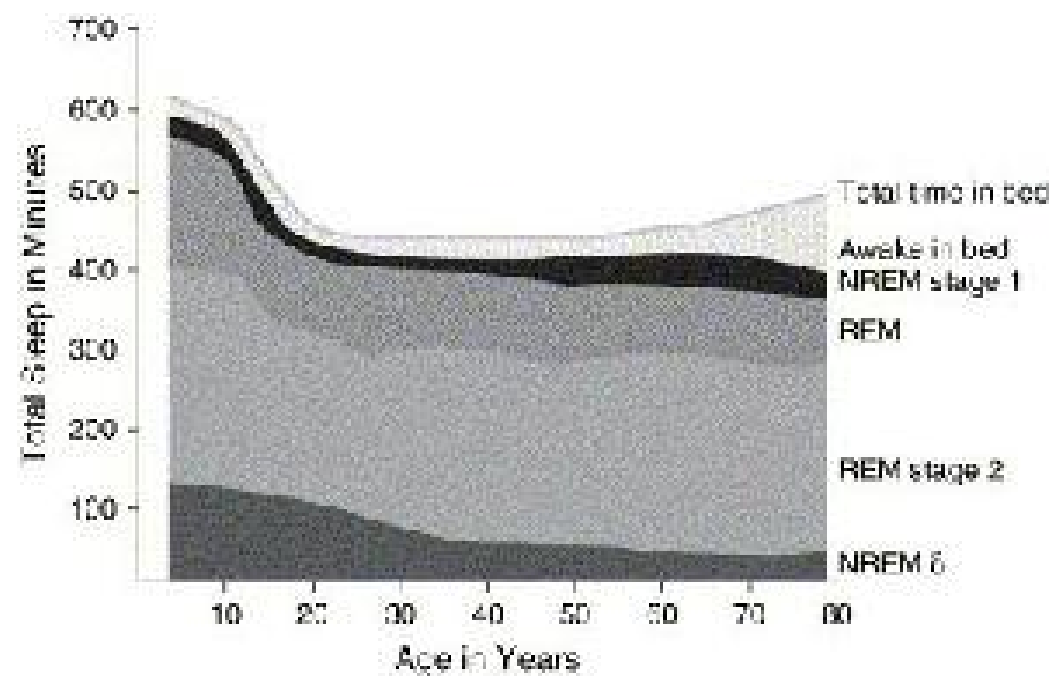

Fig. 1 Sleep and age. (Data from Williams RL, Karacan I, Hursch CJ. Electroencephalography (EEG) of human sleep: clinical applications. New York: Wiley \& Sons; 1974.)

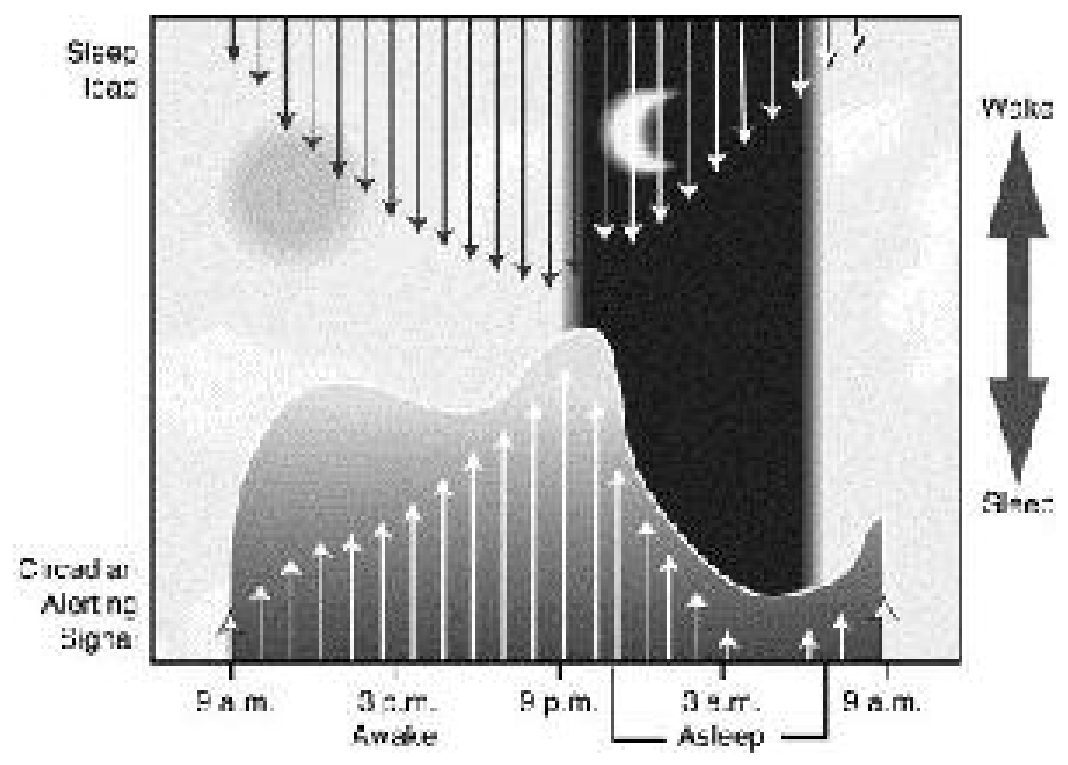

Fig. 2 Two-process model of sleep regulation. (Data from Edgar DM, Dement WC, Fuller CA. Effect of SCN lesions on sleep in squirrel monkeys: evidence for opponent processes in sleep-wake regulation. J Neurosci 1993;13:1065-79.) 


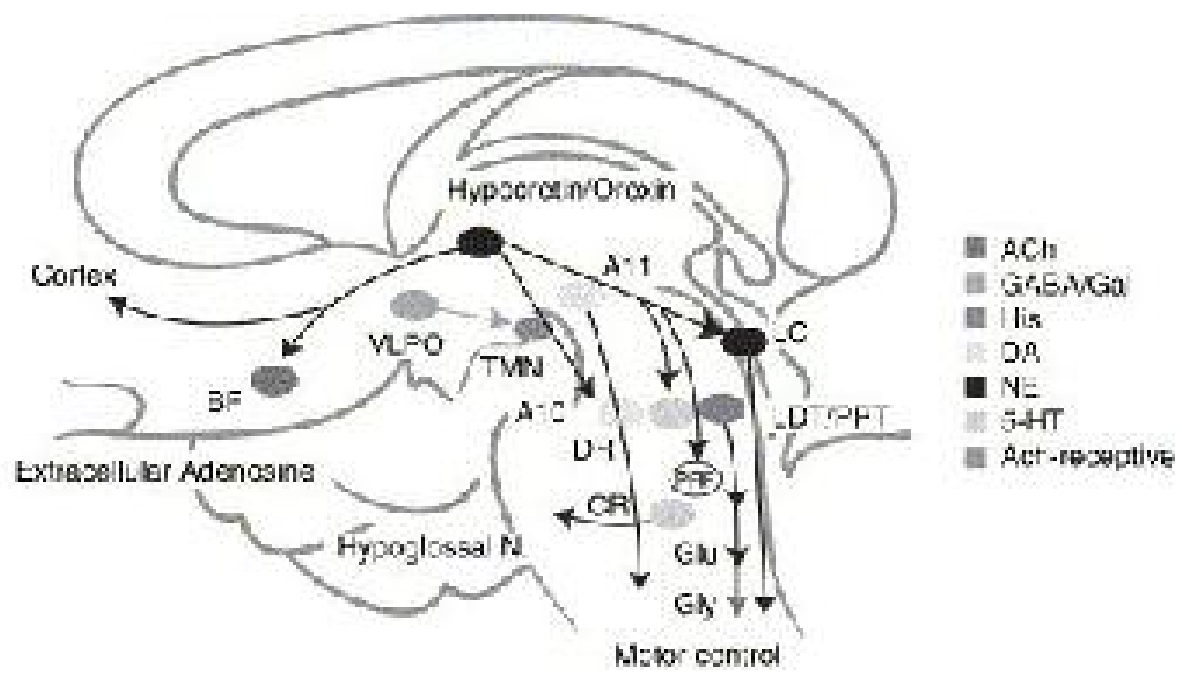

Fig. 3 Sleep: neurochemistry. BF, basal forebrain cholinergic nuclei; CR, caudal raphe; LDT/PPT, laterodorsal tegmental nuclei/pedunculopontine tegmental nuclei; PRF, pontine reticular formation; TMN, tuberomammillary nucleus; VLPO, ventrolateral preoptic nucleus. (From Mignot E, Taheri S, Nishino S. Sleeping with the hypothalamus: emerging therapeutic targets for sleep disorders. Nat Neurosci 2002;5:1072; with permission.) 